\title{
A Histological Study of the Hepatic and Renal Effects of Subchronic Low Dose Oral Monosodium Glutamate in Swiss Albino Mice
}

\begin{abstract}
Adejoke Yetunde Onaolapo ${ }^{1^{*}}$, Olakunle James Onaolapo ${ }^{2}$, Tolulope Josiah Mosaku ${ }^{1}$, Onigbinde Oluwanisola Akanji ${ }^{1}$ and Oyeleke Abiodun ${ }^{1}$

${ }^{1}$ Department of Human Anatomy Ladoke Akintola University of Technology Ogbomoso, Oyo State, Nigeria.

${ }^{2}$ Department of Pharmacology Ladoke Akintola University of Technology Ogbomoso, Oyo State, Nigeria.

Authors' contributions

This work was carried out in collaboration between all authors. Authors AYO and OJO designed the study, performed the statistical analysis, wrote the protocol, and wrote the first draft of the manuscript. Authors TJM, OOA and OA were responsible for care of the animals and bench work, they also managed the analyses of the study and the literature searches. All authors read and approved the final manuscript.
\end{abstract}

Research Article

Received $17^{\text {th }}$ August 2012 Accepted $5^{\text {th }}$ November 2012 Published $19^{\text {th }}$ January 2013

\section{ABSTRACT}

Aim: Earlier studies have shown that exposure to monosodium glutamate (MSG) in large doses during the neonatal period may result in steatohepatitis and evidence of preneoplastic changes in the liver. However, the effect of low dose, chronic oral MSG intake on the histology of the liver and kidneys have not been addressed to date, this study was designed to ascertain if MSG consumption at these doses is associated with histological evidence of hepatic or renal injuries.

Study Design: Experimental study.

Place and Duration of Study: Department of Anatomy and Department of Pharmacology Ladoke Akintola University of Technology Ogbomosho Oyo State Nigeria between October and November 2011.

Methodology: Forty adult male Swiss albino mice weighing between $20-25 \mathrm{mg}$ were 
assigned into 4 groups A, B, C and D of ten mice each $(n=10)$. Group A served as control and received normal saline while groups $B, C$ and $D$ received $M S G$ daily at $0.5,1.0$ and 1.5 $\mathrm{mg} \mathrm{MSG} / \mathrm{kg}$ body weight (BW) dissolved in normal saline respectively for 28 days. On day 29 of the study animals were sacrificed, and the liver and kidneys were removed, weighed and processed for histological examination. Statistical analysis was by one way ANOVA followed by a posthoc test, and results were expressed as mean \pm S.E.M.

Results: MSG consumption resulted in a significant increase in the relative liver weight at 1.0 and $1.5 \mathrm{mg} \mathrm{MSG} / \mathrm{Kg} \mathrm{BW}$ and a relative increase in kidney weight occurring at $1.5 \mathrm{mg} / \mathrm{Kg}$ BW $(\mathrm{P}<0.05)$. This was accompanied by a dose- dependent increase in body weight compared to control which failed to reach statistical significance. Liver and kidney histology indicated a loss of normal liver architecture with varying degrees of disorganization and apoptotic cell death compared to controls. The kidneys of MSG-exposed mice exhibited contraction of the renal glomerulus and thickening of the walls of the renal tubules.

Conclusion: The study provides evidence that oral consumption of MSG at doses within the Acceptable Daily Intake (ADI) may promote hepatic and renal injuries.

Keywords: Glutamate; anatomy; pharmacology; morphology.

\section{INTRODUCTION}

Monosodium glutamate (MSG) is a naturally occurring sodium salt of glutamic acid which was initially synthesized from wheat gluten but now produced in commercial quantities by bacterial fermentation [1]. MSG is found in some quantity in many natural food substances and as either an additive and flavor enhancer in many commercially packed food products. MSG is used in both home and restaurant cooking and it is a common component of Asian diets [2]. The unique flavor and taste of this compound has been categorized and established as a separate taste sensation "umami" taste [3]. MSG is marketed in Nigeria as Ajinomoto, other trade names include: Vetsin, Accent and Tasting powder. It is composed of white colorless odorless crystals that exist in two forms called enantiomers although only the $L$ forms are used as flavouring agents [1].The liver plays an important role in the metabolism of glutamate, some glutamate is converted here into lactate while the kidney takes part in its elimination although some MSG is metabolized by conversion into alanine in the intestinal mucosa [4]. Daily dietary composition of glutamate varies from one race to another, however daily oral consumption ranges from $0.5 \mathrm{mg} / \mathrm{kg}$ amongst Americans and over $3 \mathrm{~g} / \mathrm{kg}$ in Taiwanese diets $[5,6,7]$, the quantity of MSG consumed by Nigerians we believe would fall somewhere between 1-2.5 g/day. The Joint FAO/WHO Expert Committee on Food Additives (JECFA) evaluation in 1987 declared L-glutamate safe by arriving at an Acceptable Daily Intake (ADI) not specified" this was also reaffirmed in $2004[8,9]$.

Nakanishi et al. [10] showed that exposure to large doses of monosodium glutamate (MSG) administered to neonatal rats may result in steatohepatitis and evidence of pre-neoplastic changes in the liver. This study used relatively large doses of MSG administered during the neonatal period, when the blood-brain-barrier is immature and vulnerable to excitotoxic damage by glutamate Perez and Olney [11]. More recently, chronic exposure to low-dose MSG has been shown to result in damage to the pancreatic structures including necrotic, necrobiotic and degenerative changes to pancreatic exocrine and endocrine cells [12]. During an earlier study on the neurobehavioural effects of MSG [13], some histological changes were noticed in the liver and kidneys of some of the animals randomly selected necessitating a full evaluation of its effect on liver and kidney microanatomy at doses well below those known to be toxic. 


\section{MATERIALS AND METHOD}

\subsection{Equipments and Apparatus}

Electronic precision balance, plastic animal cages, sterile disposable syringes (1,5 and 10 $\mathrm{ml}$ ) and needles and cotton wool.

\subsection{Reagents and Drugs}

Normal Saline, 99\% monosodium glutamate (Ajinomoto brand) was purchased from the market, weighed and dissolved in isotonic saline to get desired concentrations. MSG at the varying doses $(0.5,1.0$ and $1.5 \mathrm{mg} / \mathrm{kg}$ body weight) [13] was administered orally using a cannula.

\subsection{Animals}

Healthy adult male Swiss albino mice purchased from the Empire Animal farms in Osogbo, Osun State, Nigeria were used. The animals weighed between 20 and $25 \mathrm{~g}$. After being weighed on an electronic balance, the animals were randomly divided into four treatment groups. The animals were housed in plastic cages measuring 16"x12"x10" (10 mice in each cage). All animals had access to food and water ad libitum. They were maintained under standard laboratory conditions that is a well aerated room with alternating light and dark cycles of $12 \mathrm{~h}$ each and at room temperature of $25^{\circ} \mathrm{C}$. The experimental protocol was approved by the Ladoke Akintola University Animal Ethics Committee. All rules applying to animal safety and care were observed.

\subsection{Experimental Method}

This research work was carried out between October and November 2011 in the Histology laboratory of the department of Anatomy, Ladoke Akintola University of Technology Ogbomosho. Forty animals were used for the experiment. The animals acclimatized for a period of 2 weeks following which they were were randomly assigned into four groups A, B, C and D. Group A was the control and received normal saline. Groups B, C and D received MSG orally at $0.5,1.0$ and $1.5 \mathrm{mg} / \mathrm{kg}$ body weight respectively for a period of 28 days. Animals were weighed weekly using a Mettler weighing balance (Mettler Toledo Type BD6000, Greifensee, Switzerland). At the end of the experimental period animals were observed for changes in their physical characteristics and then sacrificed by cervical dislocation and the liver and kidneys of each of the animals dissected out through a midline abdominal incision passing through the abdominal wall musculature into the peritoneal cavity. The organs were observed grossly .washed in cold saline and weighed and then fixed in $10 \%$ formolsaline for histological studies. Paraffin sections were cut and stained with Haematoxylin and Eosin for general histological study. An Olympus BX50 digital light microscope was used to examine the slides and acquire photomicrographs.

\subsection{Determination of Body Weight and Relative Liver and Kidney Weight}

Animals were weighed weekly using a Mettler weighing balance (Mettler Toledo Type BD6000, Greifensee, Switzerland. The liver and kidneys were removed and washed in cold 
saline and then weighed, to remove bias the weights of animals at sacrifice was taken and then relative weight was calculated by dividing the organ weights by body weight at sacrifice.

\subsection{Statistical Analysis}

All data were analyzed using the one way analysis of variance (ANOVA) followed by post hoc tests (Student Newman Keul's) carried out to determine the source of a significant effect. Results were expressed as Mean \pm S.E.M., $p<.05$ is taken as accepted level of significant difference from control.

\section{RESULTS}

\subsection{The Effects of Monosodium Glutamate on Relative Liver and Kidney Weight}

Fig. 1 represents the mean relative liver and kidney weight following administration of MSG. There was a significant $(F=18.05, p=.01)$ dose dependent increase in relative liver weight in the groups that received MSG at 1 and $1.5 \mathrm{mg} / \mathrm{kg}$ respectively compared to control while the relative kidney weight increased significantly $(F=22.40, p=0.02)$ at a dose of $1.5 \mathrm{mg} / \mathrm{kg}$ compared to control.

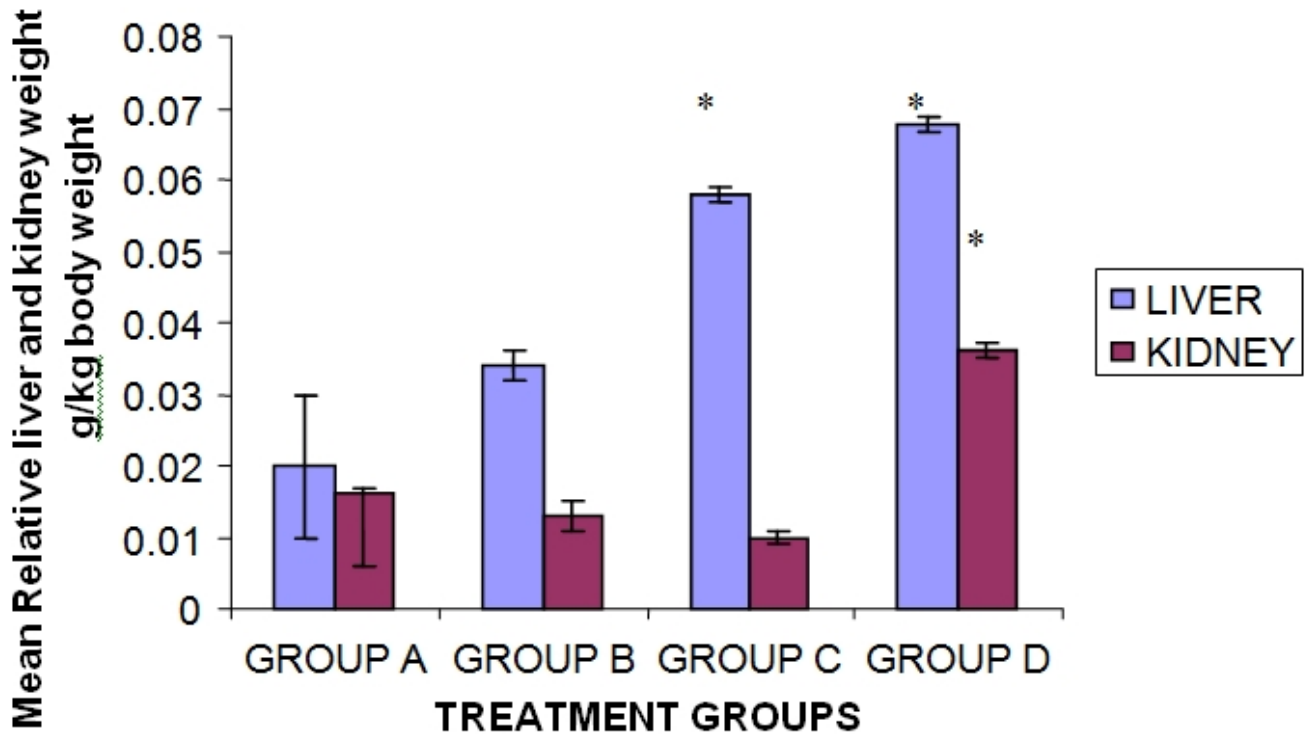

Fig. 1. Effect of MSG $(0.5,1.0,1.5 \mathrm{mg} / \mathrm{kg})$ on the mean relative liver and kidney weight. Each bar represents Mean $\pm S . E . M,{ }^{*} p \leq .05$ compared to the control, $n=10$. A control, $B$, $C$ and $D$ received $M S G$ at $0.5,1.0,1.5 \mathrm{mg} / \mathrm{kg}$ respectively

\subsection{The Effects of Monosodium Glutamate on Body Weight}

Fig. 2 represents the mean body weight taken weekly over the 28 day period. Result showed progressive reduction in body weight in groups that received MSG compared to control 
There was however no significant $(F=0.85, p=.48)$ difference in growth proportion within the groups throughout the experimental period. Comparison of the body weight in week 1 and weight in week 4 in each group revealed a dose related decrease in weight in the groups that received MSG. The animals in groups $B, C$ and $D$ had a percentage weight change of $21.25,15.88$ and $12.06 \%$ respectively compared to control group (23.37\%). These differences were however not statistically significant.

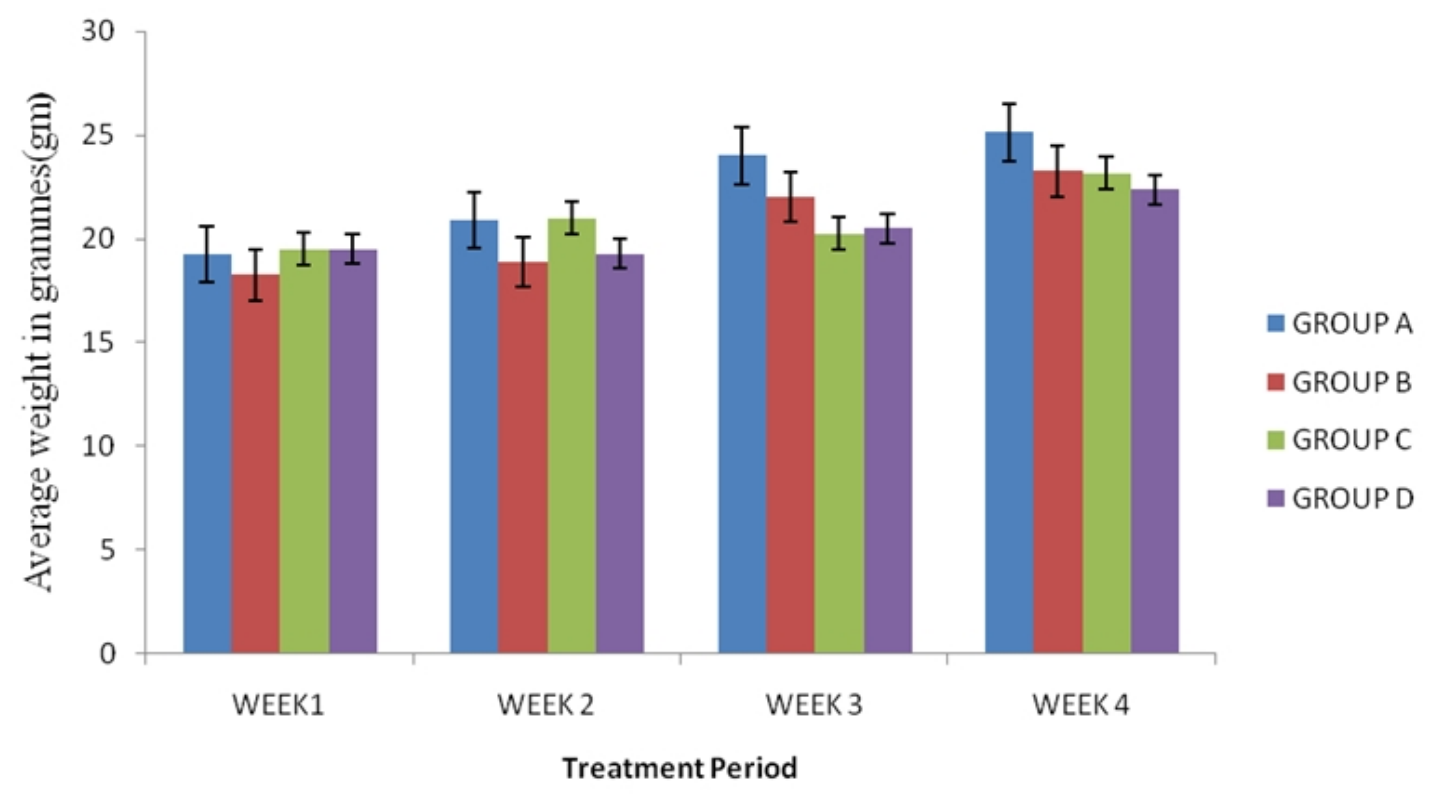

Fig. 2. Effect of MSG $(0.5,1.0,1.5 \mathrm{mg} / \mathrm{kg})$ on weekly body weight.

Each bar represents Mean $\pm S . E . M,{ }^{*} p \leq .05$ compared to the control, $n=10$. A control, $B, C$ and $D$ received $M S G$ at $0.5,1.0,1.5 \mathrm{mg} / \mathrm{kg}$ respectively.

\subsection{The Effect of Monosodium Glutamate on Liver Microanatomy}

Sections through the liver of group A animals (Plate 1), showed sheets of radially arranged hepatocytes with well demarcated nuclei and intervening sinusoids, normal central vein and hepatic artery, features in keeping with normal histology. Examination of the sections through livers of animals in groups B (Plate 2), C (Plate 3) and D (Plate 4) showed loss of liver architecture with varying degrees of liver parenchymal disorganization, cell death, dilation of the central vein and presence of inflammatory cells within and around the central vein there were also variations in the sizes and shapes of the nuclei, vacuolation and pyknosis. 


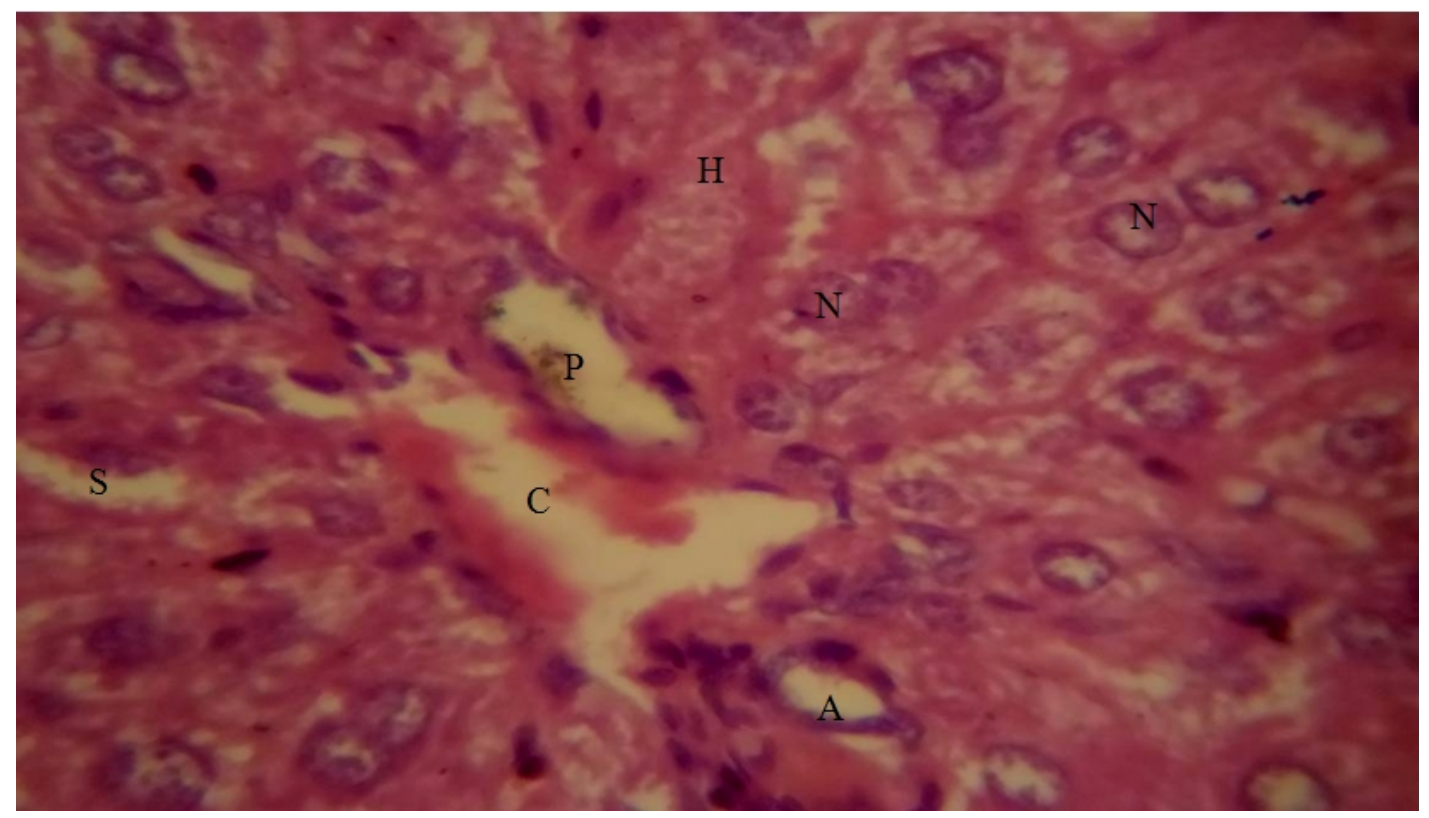

Plate 1. Photomicrograph of liver of group A animals showing radially arranged hepatocytes $(\mathrm{H})$ with well demarcated, regularly sized nuclei $(\mathrm{N})$, intervening sinusoids (S), normal central vein (C), hepatic artery (A) and portal vein (P) H\&E X400

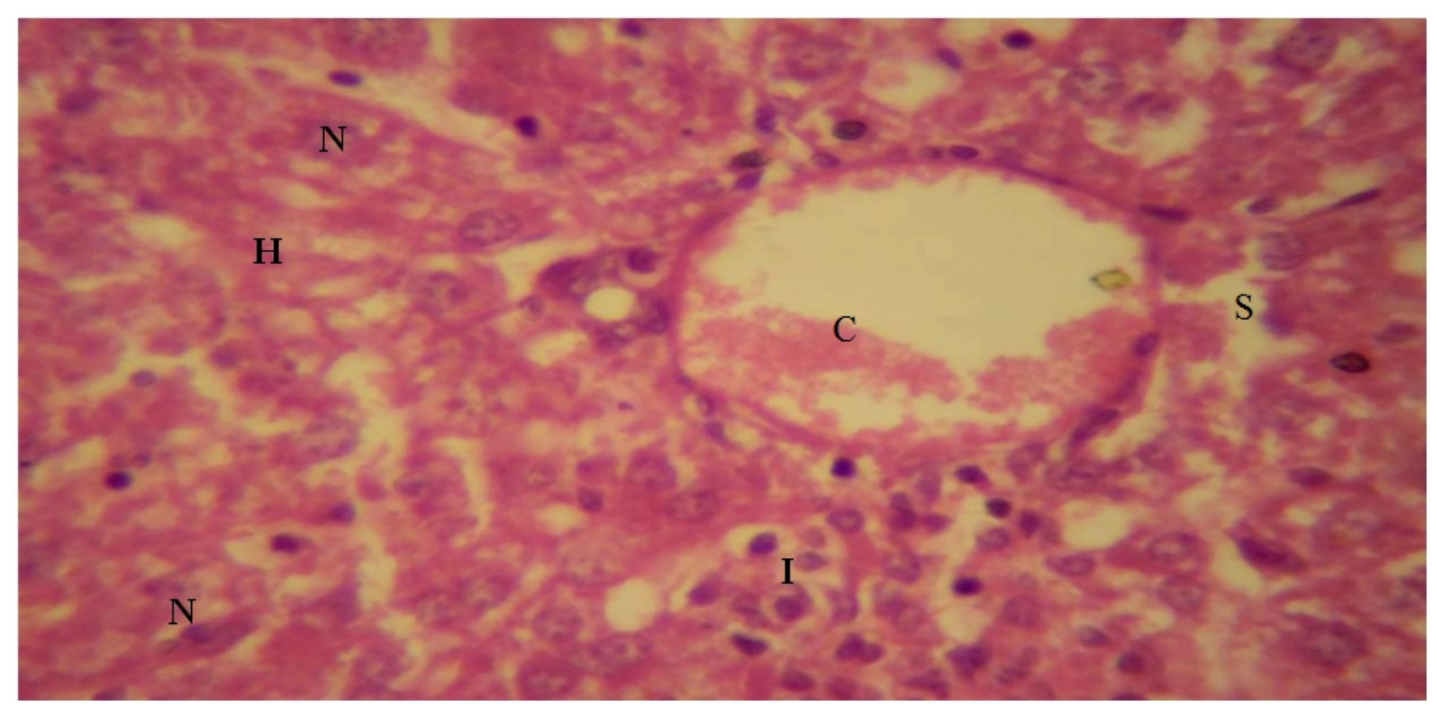

Plate 2. Photomicrograph of group B liver slides showing loss of normal architecture, degenerating hepatocytes $(\mathrm{H})$ with numerous vacuolations, nuclei $(\mathrm{N})$ of varying shapes and sizes and at varying degrees of degeneration, loss of sinusoidal spaces (S), inflammatory cells scattered all over hepatic tissue (I) and dilated central vein (C) filled with blood. H \& E X400 


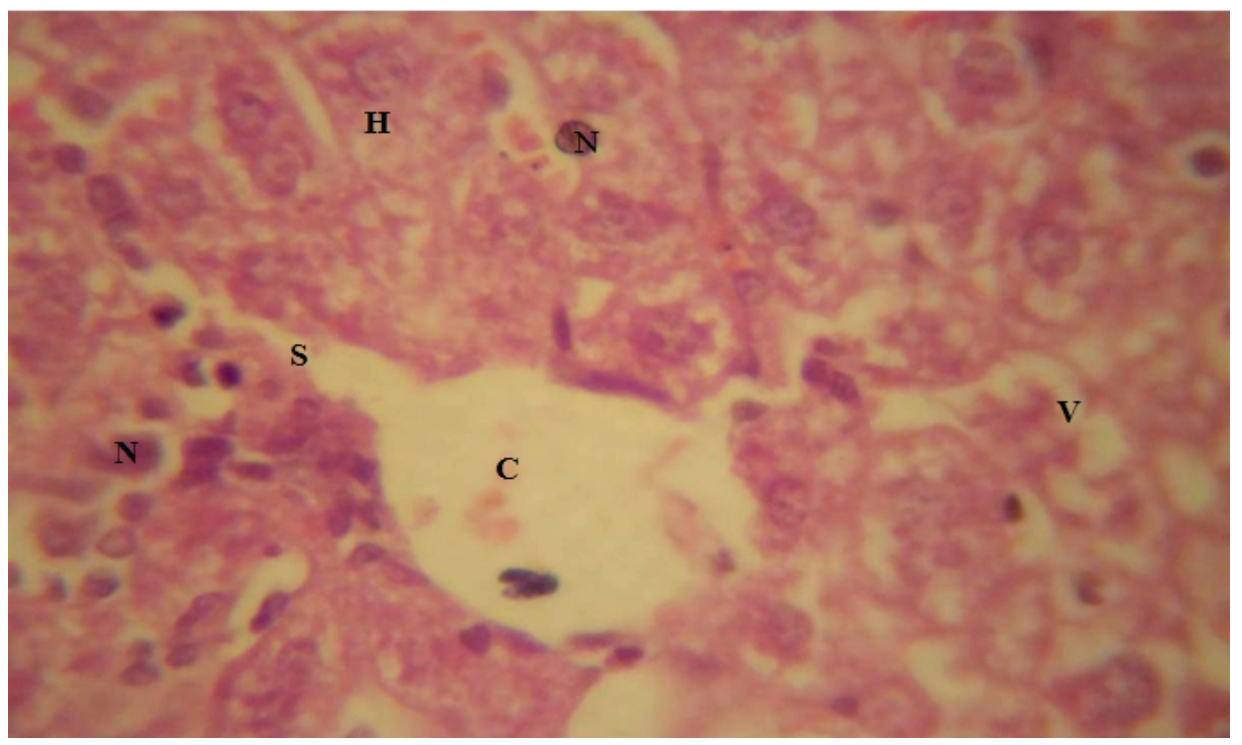

Plate 3. Photomicrograph of group $\mathrm{C}$ liver slides showing marked loss of normal liver architecture, The hepatocytes $(\mathrm{H})$ are degenerating and appear to have dropped out, numerous vacuoles are seen (V) nuclei $(\mathrm{N})$ of varying shapes and sizes mostly pycnotic are seen, nucleoli are absent and clumping of nuclear material is evident, there is also loss of normal sinusoidal space (S) and rupture of the central vein (C). $H \& E$ X400

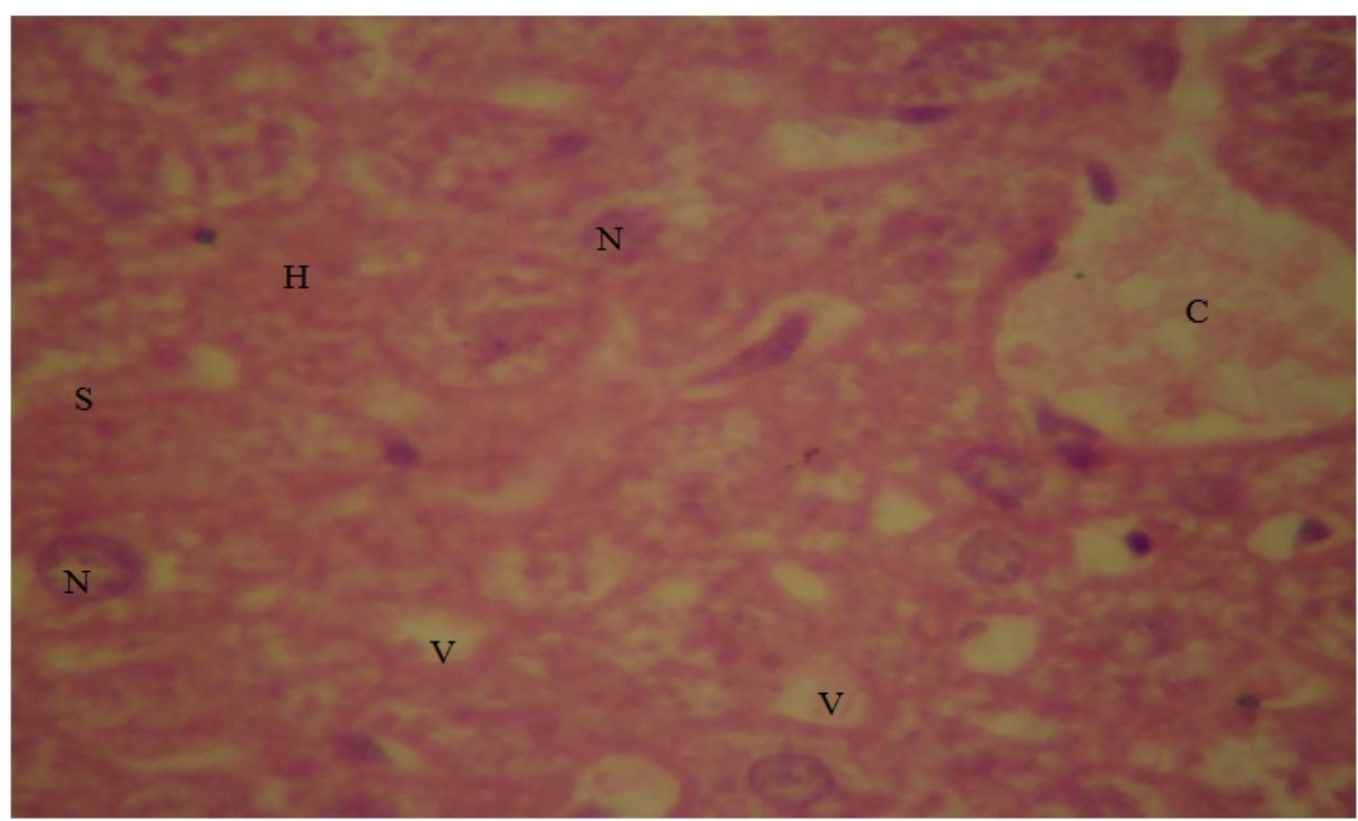

Plate 4. Photomicrograph of group $D$ liver slides showing loss of normal architecture disorganized hepatocytes $(\mathrm{H})$ with vacuolations $(\mathrm{V})$, with nuclei $(\mathrm{N})$ of varying shapes and sizes, dilated central vein (C) and loss of sinusoidal spaces (S) H\&E X400 


\subsection{Effects of Monosodium Glutamate on Kidney Microanatomy}

Sections through the kidneys of group A (Plate 5) animals showed normal kidneys with well demarcated cortex, medulla, normal Bowman's capsule and glomerulus as well as normal sized renal tubules. The sections of kidneys of groups B (Plate 6), C (Plate 7) and D (Plate 8) animals showed widening of the Bowman's space due to contraction of the renal glomerulus and hypercellularity.

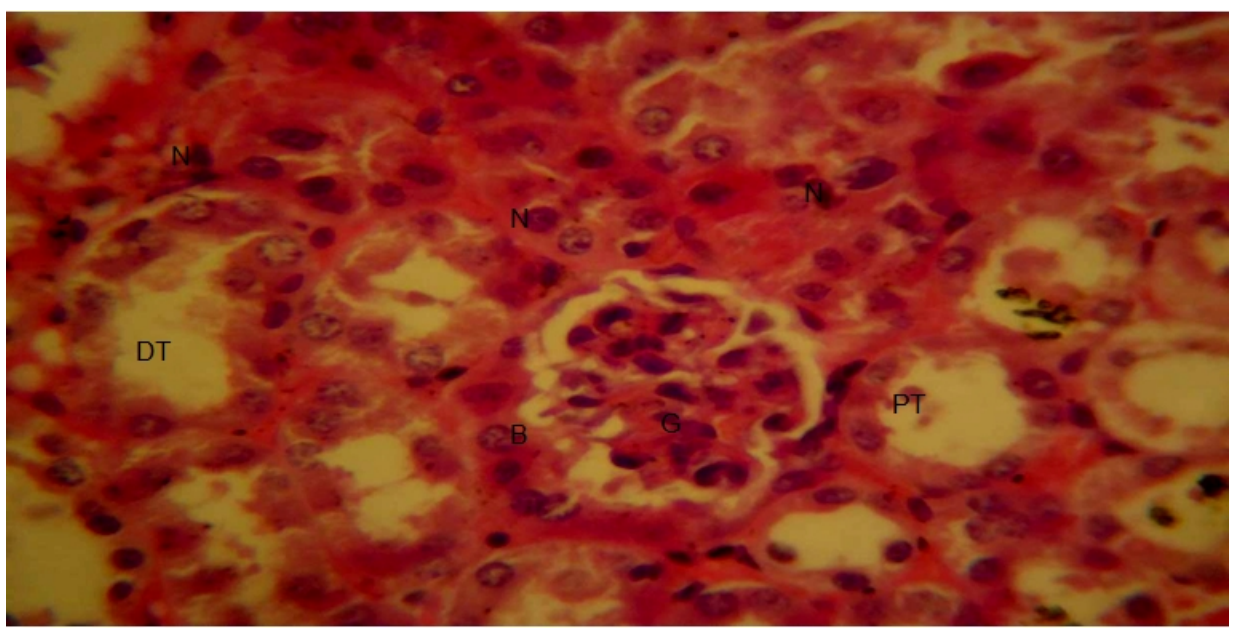

Plate 5. Photomicrograph of group A kidney slides showing normal architecture with prominent glomeruli (G) and Bowman's capsule (B) with normal sized proximal (PT) and distal tubules (DT). The renal cell nucleusare prominent and have regular sizes

(N) H\&E X400

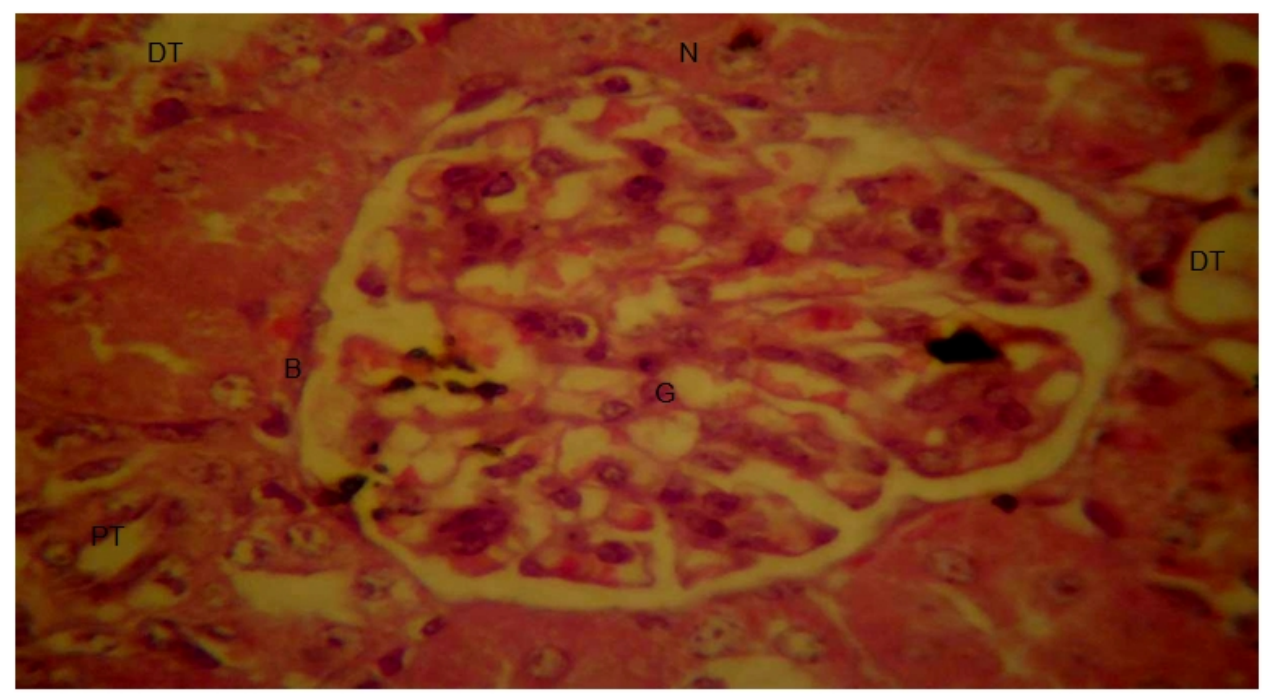

Plate 6. Photomicrograph of group B kidney slides showing grossly distended Bowman's capsule $(B)$ and glomerulus $(G)$ with contraction of the proximal and distal convoluted tubules (PT, DT),. The renal cell nuclei are not prominent and have varying shapes and sizes and at different levels of degeneration. H\&E X400 


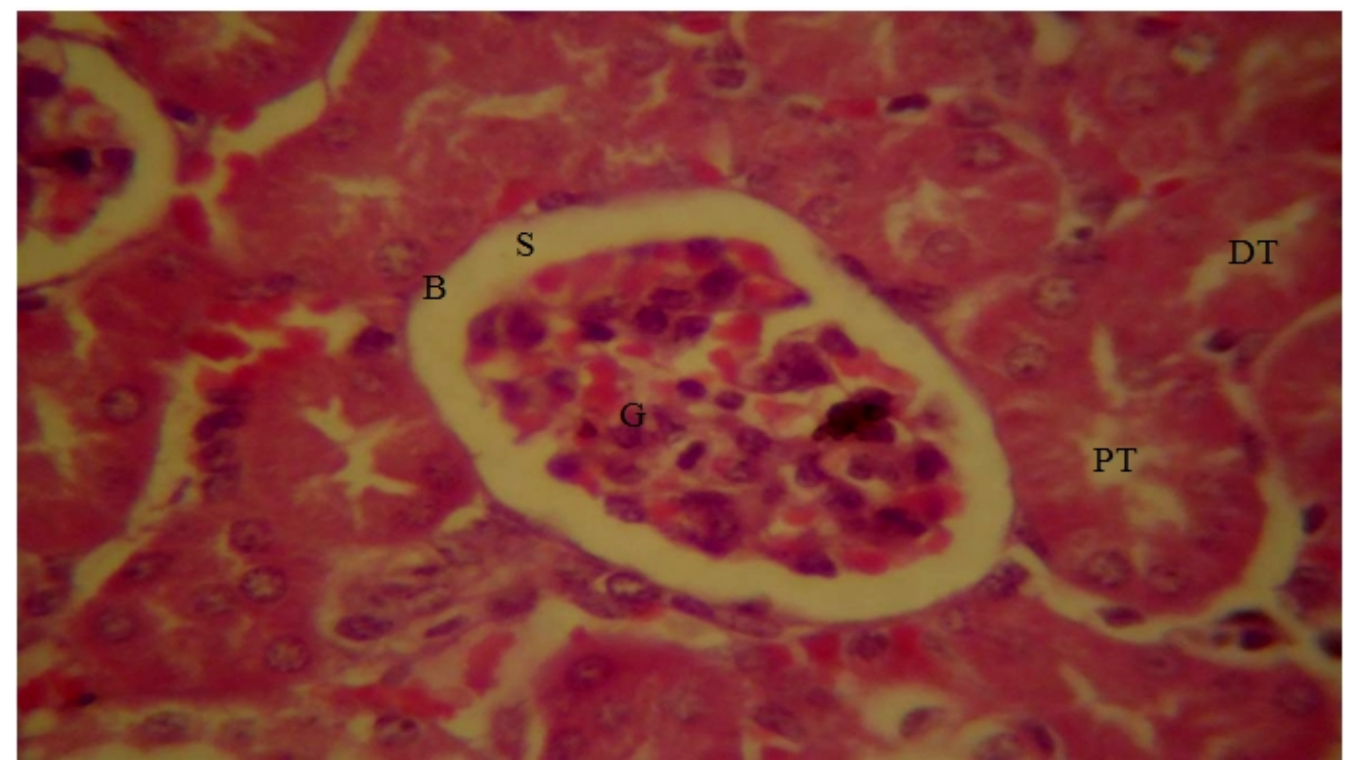

Plate 7. Photomicrograph of group C kidney slides showing the Bowman's capsule (B) with increase in the capsular space (S) from contraction of the glomerulus (G) and increased inflammatory cell within the glomerulus, the proximal and distal tubules appear normal (PT, DT), with nuclei (N) of various sizes at different levels of degeneration. H\&E X400

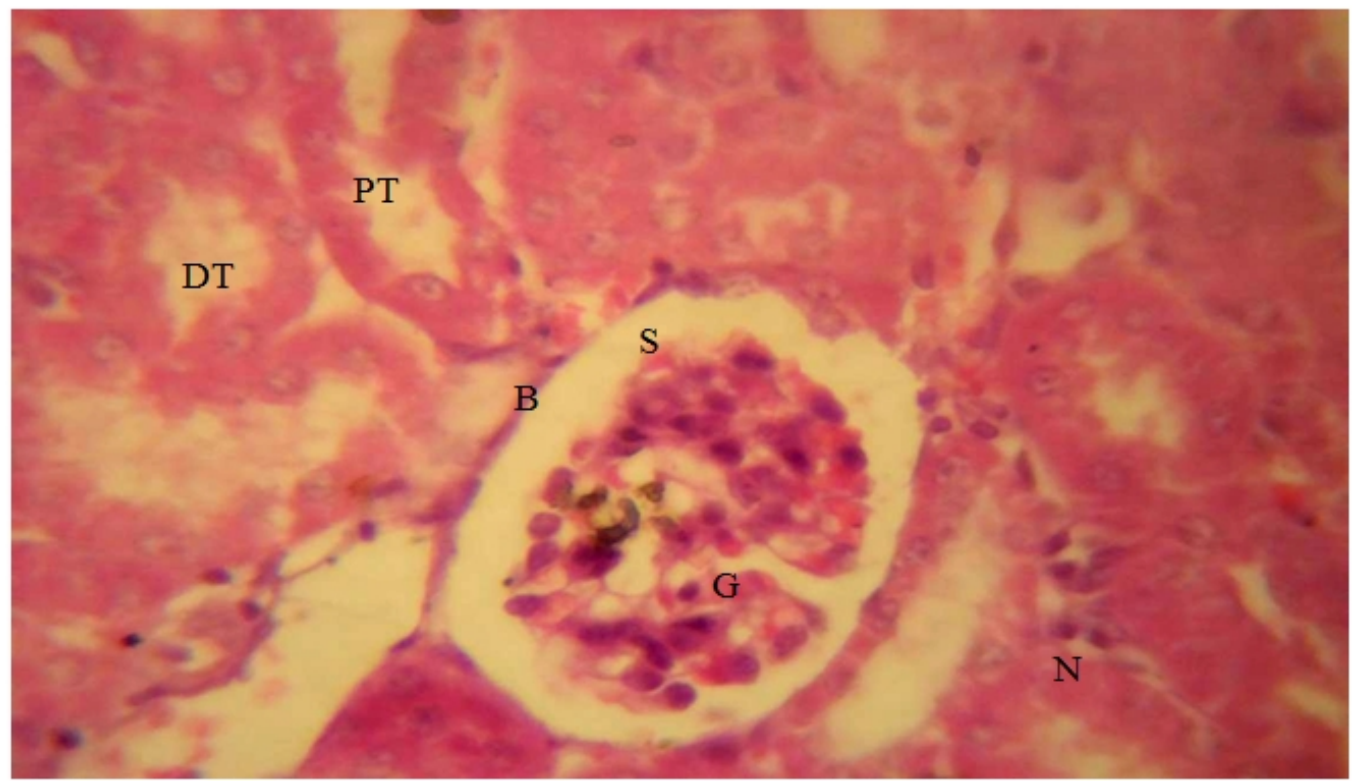

Plate 8. Photomicrograph of group D kidney slides showing the Bowman's capsule (B) with widening of the Bowman's space (S) from contraction of the glomerulus (G) and degenerating nuclei (N) the tubules however appear normal (PT, DT). H\&E X400 


\section{DISCUSSION}

Monosodium glutamate is consumed in considerable amounts in almost all forms of foods in Nigeria. MSG is one of the most extensively researched food additives in the world $[9,14]$. Results of studies continue to support the finding that at levels normally consumed as a flavor enhancer, MSG is safe for the general population [15]. In this study we evaluated the effect of subchronic oral MSG on the body weight, relative liver and kidney weight and liver and kidney morphology in mice. The results of our study revealed that at the doses of MSG tested, there was a dose related increase in body weight although the percentage weight gain reduced with increasing doses of MSG, the weight increase observed in the control group however was slightly higher compared to the MSG treatment group. A number of studies have examined the potential link between MSG and body weight. There have been speculations that people tend to eat larger helpings of food with MSG because it just tastes better than they would if the food did not contain MSG. Another school of thought suggests that MSG might interfere with signaling systems that regulate appetite centres also up scaling food consumption and hence weight gain initially and possibly obesity with chronic consumption $[16,17,18,19,20,21]$.

A significant increase in liver and kidney weight was observed following administration of MSG These could be as a result of increase in inflammatory activity with resultant tissue oedema, this is consistent with the results of liver and kidney histology that showed a lot of inflammatory cells, other studies have also documented this at higher doses of MSG [21]. In this study the liver of experimental animals showed changes in histological pattern evident by disruption of hepatic cords, presence of inflammatory cells within and around the central vein with uneven sizes of nucleus in hepatocytes. Quite a few reports on alteration in liver histology and/or biochemistry have been documented although this studies used doses that were way above the dose we chose for this study $[22,19,23,24]$. These results would mean that subchronic administration of oral MSG results in alteration in the hepatic structure that are comparable with those of studies that used doses that were at least 100-1000 times the doses in this study.

Kidney microanatomy in groups that received MSG ( $B, C$ and $D)$ compared to controls showed dilatation of the Bowman's space, contraction of the renal glomerulus and hypercellularity which are in keeping with renal injury, this corroborates results of studies carried out in 2007 by Eweka [25]. He investigated the effects of MSG on the kidney of adult Wistar rats given $3 \mathrm{~g}$ and $6 \mathrm{~g}$ of MSG thoroughly mixed with growers mash for the period of fourteen days, results of kidney microanatomy showed varying degrees of cytoarchitectural distortion and reduction in the number of renal corpuscles in the treated groups which was at variance with that of the control group. Ingestion of MSG resulted in cellular necrosis of the Bowman's capsule, at a dose of $6 \mathrm{~g}$ degeneration and atrophy of the kidneys were seen, he concluded that high doses and chronic ingestion of MSG resulted in the degenerative and atrophic changes observed in the renal corpuscle, although we used lower doses of MSG than was used by Eweka the progressive renal injury at increasing doses of MSG was evident.

The effects observed in both the liver and kidneys could have occurred because these organs are involved in the metabolism of glutamate or as in another study it may be due particularly in the liver exacerbation of trans-fat induced fatty liver disease in mice by a mechanism that includes increased central adiposity and alterations in both hepatic and white adipose tissue gene expression [26]. MSG has been reported to increase oxidative stress and some studies have also documented amelioration of the hepatotoxic or 
nephrotoxic effects by the administration of radical scavengers such as vitamin $\mathrm{E}$ or $\mathrm{C}$ $[27,28]$. The risk of hepatic or renal injury may have been increased because MSG was administered as a bolus, this school of thought is supported by Takasaki et al., who while studying the mechanisms by which glutamate induced brain injury came to the conclusions that in order to produce neurotoxic effect in infant mice MSG has to be given not only in relatively high concentration but also as a bolus solution [29].

\section{CONCLUSIONS}

This study suggests that continuous consumption of MSG in the dosage range tested herein may result in varying degrees of liver and kidney injury, depending on the concentration administered. It is important to note that the amount of MSG used in many previously published studies were very high, in contrast to the present study which showed evidence of organ injury at relatively lower doses administered chronically over a period of time. Our data suggests that further research is warranted to examine the safety profile of this widely used food additive.

\section{ETHICAL APPROVAL}

All authors hereby declare that "Principles of laboratory animal care" (NIH publication No. $85-23$, revised 1985) were followed, as well as specific national laws where applicable. All experiments have been examined and approved by the appropriate ethics committee".

All authors hereby declare that all experiments have been examined and approved by the appropriate ethics committee and have therefore been performed in accordance with the ethical standards laid down in the 1964 Declaration of Helsinki.

\section{COMPETING INTERESTS}

Authors have declared that no competing interests exist.

\section{REFERENCES}

1. Leung AY, Foster S. Monosodium glutamate. Encyclopedia of Common Natural Ingredients: Used in Food, Drugs, and Cosmetics (2nd Ed.). New York: Wiley. 2003;373-375. ISBN 978-0-471-47128-8, 2003.

2. Walker R and Lupien JR. The safety evaluation of Monosodium Glutamate J. Nutr. 2000;30(4S):1049S-1052S.

3. Ikeda K. On the taste of the salt of glutamic acid. J Tokyo Chem Soc. 1909;30:820-36.

4. Garattiini S. Glutamic Acid, Twenty Years Later. J Nutr, 2000:130: 9018-98.

5. Zhou BF, Stamler J, Dennis B, Moag-Stahlberg A, Okuda N, Robertson C, Zhao L, Chan $Q$, Elliott $P$. Nutrient intakes of middle-aged men and women in China, Japan, United Kingdom, and United States in the late 1990s: the INTERMAP study. J Hum Hypertens. 2003;17(9):623-30.

6. He K, Zhao L, Daviglus ML, Dyer AR, Van Horn L, Garside D, Zhu L, Guo D, Wu Y, Zhou B, Stamler J. Association of monosodium glutamate intake with overweight in Chinese adults: the INTERMAP Study. Obesity. 2008;16(8):1875-1880. 
7. Shi Z, Luscombe-Marsh ND, Wittert GA, Yuan B, Dai Y, Pan X, Taylor AW. Monosodium Glutamate is not associated with obesity or a greater prevalence of weight gain over 5 years: findings from the Jiangsu Nutrition Study. $\mathrm{Br} J$ Nutr. 2010;104(3):457-463.

8. Joint FAO/WHO Expert Committee on Food Additives (JECFA) Evaluation of certain food additives: Thirty -first report of the Joint FAO/WHO Expert Committee on Food Additives. WHO technical report series. 1987;928:108.

9. Joint FAO/WHO Expert Committee on Food Additives (JECFA) Evaluation of certain food additives: sixty-third report of the Joint FAO/WHO Expert Committee on Food Additives. WHO technical report series. 2004;928:108.

10. Nakanishi Yuko, Tsuneyama Koichi, Fujimoto Makoto, Salunga. Thucydides L. Kazuhiro Nomoto et al., Monosodium glutamate (MSG): A villain and promoter of liver inflammation and dysplasia. J of Autoimmunity. 2008;30(1-2):42-50

11. Perez VJP, Olney JW. Accumulation of glutamic acid in the arcuate nucleus of the hypothalamus of the infant mouse following subcutaneous administration of monosodium glutamate, J. of Neurochemistry. 1972;19(7):1777-1782

12. Falalyeyeva TM, Leschenko IV, Shevchuk VO, Beregova TV. About the influence of long-term injection of monosodium glutamate on pancreas in rats. Euro J. of Clinical Investigation. 2012;42(s1):5

13. Onaolapo Olakunle James, Onaolapo Adejoke Yetunde. Acute low dose monosodium glutamate retards novelty induced behaviours in male swiss albino mice. J. of Neuroscience and Behav. Health. 2011;3(4):51-56. ISSN 2141-2286.

14. Federation of American Societies for Experimental Biology (FASEB). Analysis of adverse reactions to monosodium glutamate (MSG). Bethesda, MD: Life Sciences Research Office; 1995.

15. Hodgson Aurora Saulo. Some facts about monosodium glutamate (MSG), Foods and Nutrition 2001;FN-8.

16. Bergen HT, Mizuno TM, Taylor J. Hyperphagia and Weight Gain after GoldThioglucose and Monosodium Glutamate: Relation to Hypothalamic Neuropeptide. Endocrinol. 1998;139(11):4483-4488. http://dxdoi:10.1210/en.139.11.4483

17. Mozes S, Sefcikova Z, Lenharde L, Raeek L. Obesity and changes of alkaline phosphatase activity in the small intestine of 40-80-day old subjects to early postnatal overfeeding of monosodium glutamate. Physiological Res. 2004;53:177-186.

18. Kawakita T, Chiaki S, Shigeru S, Masahiro T, Shizuko Y. Monosodium Glutamate. Ullmann's Encyclopedia of Industrial Chemistry; 2005.

19. Inuwa HM, Aina VO, Baba Gabi, Aim I. ola, Leehman Ja'afaru. Determination of nephrotoxicity and hepatoxicity of monosodium glutamate (MSG) consumption. British J. of Pharm and Tox. 2011;2(3):148-153. ISSN:2044-246.

20. Bhattacharya T, Bhakt A, Ghosh HM. Long term effect of monosodium glutamate in liver of albino mice after neo-natal exposure Nepal Med College J. 2011;13(1):11-16

21. Tawfik Manal Said, Al-Badr Nawal. Adverse effects of monosodium glutamate on liver and kidney functions in adult rats and potential protective effect of vitamins $\mathrm{C}$ and $\mathrm{E}$ Food and Nutrition Sciences, 2012;(3):651-659. doi:10.4236/fns.2012.35089.

22. Eweka AO, Om'Iniabohs FAE. Histochemical studies of the effects of Monosodium glutamate on the liver of Wistar rats. Annals Med Health Sci Res;2001; 1: 21-9.

23. Egbuonu ACC, Obidoa O, Ezeokonkwo CA, Ezaeanyika LUS, Ejikeme PM. Hepatotoxic effects of low dose oral administration of monosodium glutamate in male albino rats. Afr. J. Biotech. 2009;8(13):3031-3035.

24. Ortiz GG, Bitzer-Quintero OK, Zarate CB. Monosodium glutamate induced damage in liver and kidney; A morphological and biochemical approach. Biomedicine Pharmacotherapy. 2006;50:86-9. 
25. Eweka AO. Histological studies of the effect of monosodium glutamate on the kidney of adult Wistar rats. Internet J. of Health. 2007;6(2). ISSN: 1528-8315.

26. Collison KS, Maqbool Z, Saleh SM, Inglis A, Makhoul NJ, Bakheet R, et al. Effect of dietary monosodium glutamate on trans fat-induced nonalcoholic fatty liver disease. $\mathrm{J}$ Lipid Res, 2009;50(8):1521-37.

27. Farombi EO, Onyema OO. Monosodium glutamate induced oxidative damage and geno toxicity in rat modulatory role of vitamin $C$, vitamin $E$ and quercetin. Human Exptl Tox. 2006;25:251-259 http://dx.doi.org/10.1191\%2.

28. Onyema OO, Farombi EO, Emerole GO, Ukoha AI, Onyeze GO. Effect of vitamin E on monosodium glutamate induced hepatotoxic and oxidative stress in rats. Indian $\mathrm{J}$. Biochemistry. Biophysiology. 2006;43:20-24.

29. Takasaki Y, Matsuzawa Y, Iwata S, O'hara Y, Yonetani S, Ichimura M. Toxicological studies of monosodium L-glutamate in rodents; relationship between routes of administration and neurotoxicity. In: Glutamic Acid: Advances in Biochemistry. 1979;255-275. Raven Press, New York.

(C) 2013 Onaolapo et al.; This is an Open Access article distributed under the terms of the Creative Commons Attribution License (http://creativecommons.org/licenses/by/3.0), which permits unrestricted use, distribution, and reproduction in any medium, provided the original work is properly cited.

Peer-review history:

The peer review history for this paper can be accessed here: http://www.sciencedomain.org/review-history.php?iid=177\&id=12\&aid=847 